\title{
Fear of Coronavirus, Emotional Eating Behaviours, and Physical Activity Levels during the Coronavirus Pandemic in Individuals Over 65 Years of Age
}

\begin{abstract}
Sabriye Ercan ${ }^{1}$, Ahsen Oğul ${ }^{2 *}$, Furkan Hasan Küçük ${ }^{1}$, Cem Çetin $^{1}$
${ }^{1}$ Süleyman Demirel University, Faculty of Medicine, Department of Sports Medicine, Isparta, Turkey.

${ }^{2}$ Gazi Yaşargil Education and Research Hospital, Department of Sports Medicine, Diyarbakır, Turkey.
\end{abstract}

\begin{abstract}
The Covid-19 pandemic has led to dramatic changes in lifestyle across populations. This study aimed to investigate the relationship between fear of Coronavirus, emotional eating behaviour and physical activity levels in individuals aged >65 years, and to determine the differences between individuals who did and did not gain weight during the pandemic. The study included individuals aged $>65$ years who were not diagnosed with Coronavirus disease (Covid-19). Participants' demographic information, Fear of Covid-19 Scale scores, Emotional Eater Questionnaire (EEQ) scores, and physical activity levels according to the General Practice Physical Activity Questionnaire (GPPAQ) were recorded with an online questionnaire. The study included a total of 156 participants (72 females, 46.2\%; 84 males, $53.8 \%)$. The average age was $71.86 \pm 7.13$ years. The average change in body mass index (BMI) between February 2020 and January 2021 was $0.80 \pm 1.32 \mathrm{~kg} / \mathrm{m}^{2}$. Participants were divided into two according to change in body mass index during the pandemic as weight-gain $(W G, n=104)$ and non-weight-gain $(N W G, n=52)$ groups. The two groups were not different in terms of descriptive characteristics, the Fear of Covid-19 Scale scores, and physical activity levels ( $p>0.05)$. The WG group scored statistically higher in EEQ, and the EEQ typeof-food subscale ( $p=0.027, p=0.029$, respectively). Current BMI, overall EEQ score, and EEQ disinhibition and type-of-food subscores were weakly positively correlated with the change in BMI $(p<0.05)$. EEQ guilt subscores were weakly positively correlated with the age $(p<0.05)$. The change in BMI during the Covid-19 quarantine was associated with the EEQ overall score and its subscales among elderly adults. Physical activity levels of groups were similar and participants who gained weight were more prone to emotional eating.
\end{abstract}

Key words: Covid-19, Fear of Coronavirus, Emotional eating, Physical activity, Elderly.

*Corresponding Author: Ahsen Oğul, Tel: +90 554795 9011, E-mail: ahsenogul91@gmail.com. ORCID ID:0000-0001-7379-0750. 


\section{S. Ercan et al.}

\section{Introduction}

An infectious disease emerged in Wuhan, China in December 2019 and was declared a pandemic by the World Health Organization in March 2020. The disease, caused by the novel Coronavirus (SarsCoV-2) and named the Coronavirus disease 2019 (Covid-19), is still a major global health problem (1). As of February 2021, more than 107 million people were infected and more than 2.3 million died due to Covid-19 around the world. In Turkey, there have been more than 2.5 million cases of Covid-19 and more than 27 thousand related deaths $(2,3)$.

There is ongoing concern about the psychological impact of the pandemic on the elderly (4). Previous studies established that infection outbreaks result in a wide range of effects on individual and public mental health (5). For instance, a study concerning the SARS epidemic associated the fear of infection with post-traumatic stress symptoms (6). Ahorsu et al. conducted a study to investigate the impact of the Covid-19 outbreak and found that fear of Covid-19 was correlated with depression, anxiety, and germ aversion behaviours (7). Another study found an association between drinking and smoking habits and Fear of Covid-19 scores (8). Numerous studies have confirmed the link between fear of Covid-19 and anxiety and depression (9). On the other hand, fear can impact social and physical activity participation, as well as causing a tendency to overeat as a coping mechanism to regulate and reduce negative emotions (10).

Staying at home for extended periods of time and the lockdown affect daytime routines, work schedules, and lifestyle habits (11). Decreased physical activity, along with prolonged inactivity, leads to poor quality eating behaviour, resulting in involuntary weight gain. Inactivity is associated with hypertension and impaired glucose tolerance and increases the risk of cardiovascular and metabolic diseases in individuals over the age of 65 , who have become increasingly inactive during the Coronavirus pandemic (11). A Japanese study reported that physical activity participation of the elderly population was significantly reduced from January 2020 to April $2020(\mathrm{p}<0.001)$ and argued that this may result in severe health problems in the future (1).

Weight gain may be inevitable when physical inactivity is combined with emotional eating behaviours to escape or distract from emotional hardship (10). The negative emotional consequences of the global Covid-19 crisis associated with deaths, compulsory quarantine, and economic disruption, feelings of isolation, fear of infection, stress, and the interruption of daily life potentially increase emotional eating behaviour (10). A systematic review of 62 studies that included 162639 participants from 17 countries including China, Turkey, Iran, Spain, and Italy reported that the prevalence of Covid-19-related anxiety and depression were $33 \%$ and $28 \%$, respectively (12). These results reflect the psychological impact of the Covid-19 pandemic on the Turkish population.

The literature on physical activity, obesity, and weight gain among the elderly during the pandemic is very limited. Recent studies have focused on the psychological effects of the lockdown (13), and it is clear that more data is needed on the fear of illness, eating behaviours, and physical activity levels of individuals over 65 . This study aimed to investigate the fear of Coronavirus, emotional eating behaviour, 


\section{S. Ercan et al.}

and physical activity levels among individuals aged $>65$ years and to compare these parameters between individuals who did and did not gain weight during the pandemic.

\section{Materials and Methods}

This is a cross-sectional survey study. The study was granted approval by the local ethics committee (date 30.12.2020 and number 416) and the Republic of Turkey Ministry of Health Directorate General of Health Services.

The study included individuals aged $>65$ years who lived in Turkey and were literate in Turkish, and who did not have a diagnosis of Covid-19. Participants were selected using snowball sampling. Voluntary participants were asked to complete the online questionnaire (Google Forms) with help from digitally literate individuals.

Individuals diagnosed with Covid-19, individuals who inadequately completed the questionnaire, and those younger than 65 were excluded from the study.

Participants' demographic information, Fear of Covid-19 Scale scores (14), Emotional Eater Questionnaire (EEQ) scores (15), and physical activity levels according to the General Practice Physical Activity Questionnaire (GPPAQ) (16) were recorded.

Fear of Covid-19 Scale:

This scale was developed to measure individuals' fear of Covid-19. All items are positively worded. The total score indicates the level of fear of Covid-19. The minimum possible score is 7 and the maximum possible score is 35 . A higher score indicates a higher fear of Covid-19 (14).

Emotional Eater Questionnaire (EEQ):
This 10-item 4-point Likert-type questionnaire consists of three subscales: disinhibition, type-of-food, and guilt. All items are positively worded. The minimum possible score is 0 and the maximum possible score is 30. A higher score indicates increased emotional eating (15).

Garaulet et al. (17) indicate that individuals that score 11 and higher on the EEQ are "emotional eaters".

General Practice Physical Activity Questionnaire (GPPAQ):

This 7-item three-part questionnaire was adapted to Turkish and validated by Noğay et al. The first part of the GPPAQ investigates physical activity involved in the person's work, the second part investigates physical activities performed within the previous week, and their durations, and the last part, the person's walking speed. The questionnaire evaluates physical activity in four categories, namely active, moderately active, moderately inactive, and inactive (16).

\section{Statistical Analysis}

Data were analyzed using SPSS software package v.23. Participants' descriptive characteristics were presented as frequencies, percentages, and mean \pm standard deviation. Conformity of the data to normal distribution was evaluated by the Shapiro-Wilk test. The difference between the mean BMI values of participants who did and did not gain weight during the pandemic was examined by the Mann-Whitney $U$ and chi-square tests. We investigated the relationship between the change in body mass index $(\triangle B M I)$, age and other variables using Spearman's correlation analysis. A $\mathrm{p}$ value $<0.05$ was accepted as statistically significant. 


\section{S. Ercan et al.}

\section{Results}

A total of 214 people responded to the online questionnaire in January 2021. 58 participants were excluded due to being aged $<65$ years $(n=35)$, having a COVID19 diagnosis $(\mathrm{n}=15)$, and inadequate completion of the questionnaire, i.e., having a $\mathrm{Z}$ score outside the range of $[-4,4]$ $(n=8)$. Thus, the final analysis included 156 participants.

Among these, $46.2 \%(n=72)$ were female and $53.8 \%(n=84)$ were male. The mean age of the participants was $71.86 \pm 7.13$ years (Table 1). The mean pre-pandemic BMI (February 2020) was $26.60 \pm 3.92 \mathrm{~kg} / \mathrm{m}^{2}$, the mean current BMI (January 2021) was $27.41 \pm 4.23 \mathrm{~kg} / \mathrm{m}^{2}$, and the mean change in BMI $(\triangle \mathrm{BMI})$ was $0.80 \pm 1.32 \mathrm{~kg} / \mathrm{m}^{2}$.

Participants were divided into two according to the change in body mass index during the pandemic as weight-gain (WG, n=104) and non-weight-gain (NWG, $\mathrm{n}=52$ ) groups. For the WG group, the mean age was $71.85 \pm 7.18$ years, February 2020 BMI was $26.52 \pm 3.97 \mathrm{~kg} / \mathrm{m}^{2}$, January 2021 BMI was $27.97 \pm 4.34 \mathrm{~kg} / \mathrm{m}^{2}$, and mean $\triangle B M I$ was $1.45 \pm 1.02 \mathrm{~kg} / \mathrm{m}^{2}$. For the NWG group, the mean age was $71.88 \pm 7.10$ years, February 2020 BMI was $26.77 \pm 3.84 \mathrm{~kg} / \mathrm{m}^{2}$, January 2021 BMI $26.27 \pm 3.78 \mathrm{~kg} / \mathrm{m}^{2}$, and mean $\Delta \mathrm{BMI}$ was $-0.50 \pm 0.75 \mathrm{~kg} / \mathrm{m}^{2}$. The two groups were similar in terms of mean age ( $\mathrm{p}=0.890)$ and February 2021 BMI $(\mathrm{p}=0.481)$ but significantly different in terms of current BMI $(\mathrm{p}=0.018)$ and $\triangle \mathrm{BMI}$ $(p=0.0001)$. The two groups were similar in terms of sex distribution, educational status, marital status, income level, known diseases, and drug use ( $\mathrm{p}>0.05)$ (Table 1). The participants in the NWG group were more likely to have first-degree relatives diagnosed with Covid-19 (34.6\% vs. 15.4\%; $\mathrm{p}=0.011)$. 


\section{S. Ercan et al.}

Table 1: Mean age and gender of the participants, socio-economic status, whether they have chronic diseases and drug use.

\begin{tabular}{|c|c|c|c|c|}
\hline & All, $n=156$ & WG, $n=104$ & NWG, $n=52$ & p value \\
\hline \multicolumn{5}{|c|}{ mean \pm SD } \\
\hline Age (Years) & $71.86 \pm 7.13$ & $71.85 \pm 7.18$ & $71.88 \pm 7.10$ & 0.890 \\
\hline \multicolumn{5}{|c|}{$\%(n)$} \\
\hline Gender (Male / Female) & $\begin{array}{l}53.8 \%(84) / \\
46.2 \%(72)\end{array}$ & $\begin{array}{c}53.8 \%(56) / \\
46.2 \%(48)\end{array}$ & $\begin{array}{l}53.8 \%(28) / \\
46.2 \%(24)\end{array}$ & 1 \\
\hline Education status & & & & 0.728 \\
\hline Primary education & $53.8 \%(84)$ & $52.9 \%(55)$ & $55.7 \%(29)$ & \\
\hline Secondary education & $15.4 \%(24)$ & $16.3 \%(17)$ & $13.5 \%(7)$ & \\
\hline Post-secondary education & $21.8 \%(34)$ & $20.2 \%(21)$ & $25 \%(13)$ & \\
\hline Master's Degree/Doctorate & $9 \%(14)$ & $10.6 \%(11)$ & $5.8 \%(3)$ & \\
\hline $\begin{array}{l}\text { Marital status (Married / } \\
\text { Single) }\end{array}$ & $\begin{array}{l}82.1 \%(128) / \\
17.9 \%(28)\end{array}$ & $\begin{array}{l}82.7 \%(86) / \\
17.3 \%(18)\end{array}$ & $\begin{array}{l}80.8 \%(42) / \\
19.2 \%(10)\end{array}$ & 0.941 \\
\hline Income status & & & & 0.217 \\
\hline Income<expenses & $17.3 \%(27)$ & $15.4 \%(16)$ & $21.2 \%(11)$ & \\
\hline Income $=$ expenses & $40.4 \%(63)$ & $37.5 \%(39)$ & $46.1 \%(24)$ & \\
\hline Income>expenses & $42.3 \%(66)$ & $47.1 \%(49)$ & $32.7 \%(17)$ & \\
\hline Chronic diseases (Yes / No) & $\begin{array}{c}70.5 \%(110) / \\
29.5 \%(46)\end{array}$ & $\begin{array}{c}75 \%(78) / 25 \% \\
(26)\end{array}$ & $\begin{array}{l}61.5 \%(32) / \\
38.5 \%(20) \\
\end{array}$ & 0.121 \\
\hline Mental illness (Yes / No) & $\begin{array}{l}14.1 \%(22) / \\
85.9 \%(134)\end{array}$ & $\begin{array}{l}14.4 \%(15) / \\
85.6 \%(89)\end{array}$ & $\begin{array}{l}13.5 \%(7) / \\
86.5 \%(45)\end{array}$ & 1 \\
\hline Chronic drug use (Yes / No) & $\begin{array}{c}60.9 \%(95) / \\
39.1 \%(61)\end{array}$ & $\begin{array}{c}65.4 \%(68) / \\
34.6 \%(36)\end{array}$ & $\begin{array}{c}51.9 \%(27) / \\
48.1 \%(25)\end{array}$ & 0.147 \\
\hline
\end{tabular}

$5.1 \%$ of all participants were physically inactive, $23.1 \%$ were moderately inactive, $30.1 \%$ were moderately active, and $41.7 \%$ were active. The two groups were not statistically different in terms of physical activity (Table 2).

Table 2: Physical activity levels

\begin{tabular}{lcccc}
\hline & All, $\mathbf{n = 1 5 6}$ & WG, $\mathbf{n = 1 0 4}$ & NWG, $\mathbf{n = 5 2}$ & P value \\
\hline Inactive & $5.1 \%(8)$ & $3.8 \%(4)$ & $7.7 \%(4)$ & 0.402 \\
\cline { 1 - 4 } Moderately Inactive & $23.1 \%(36)$ & $20.2 \%(21)$ & $28.8 \%(15)$ & \\
\hline Moderately Active & $30.1 \%(47)$ & $31.7 \%(33)$ & $26.9 \%(14)$ & \\
\hline Active & $41.7 \%(65)$ & $44.2 \%(46)$ & $36.6 \%(19)$ & \\
\hline
\end{tabular}

\%: percentage, n: number WG: Gain Weight, NWG: Not Gain Weight. As determined by the chi-square test.

For all participants, the mean total Fear of Covid-19 score was $22.67 \pm 6.59$, and not significantly different for the two groups (Table 3). On the other hand, the two groups were statistically different in terms of EEQ total score and type-of-food subscores. The number of participants evaluated as "emotional eaters" (EEQ score $\geq 11$ ) was not significantly different for the two groups (Table 3). When the participants were divided according to age as 65-74 years old and over 75 years old, a statistically significant difference was found in the EEQ total score between the group that gained weight and the group that non-gained weight (Table 4). 


\section{S. Ercan et al.}

Table 3: Scale Results.

\begin{tabular}{lcccc}
\hline & All, $\mathbf{n}=\mathbf{1 5 6}$ & WG, $\mathbf{n = 1 0 4}$ & NWG, $\mathbf{n = 5 2}$ & P value \\
\hline Fear of Covid-19 score & $22.67 \pm 6.59$ & $22.88 \pm 6.59$ & $22.25 \pm 6.63$ & 0.390 \\
\hline EEQ score & $7.26 \pm 5.16$ & $7.76 \pm 4.80$ & $6.25 \pm 5.72$ & $\mathbf{0 . 0 2 7} *$ \\
\hline Disinhibition & $4.04 \pm 3.33$ & $4.29 \pm 3.14$ & $3.54 \pm 3.65$ & 0.060 \\
\hline Type of food & $2.06 \pm 1.36$ & $2.23 \pm 1.31$ & $1.73 \pm 1.40$ & $\mathbf{0 . 0 2 9 *}$ \\
\hline Guilt & $1.15 \pm 1.31$ & $1.24 \pm 1.33$ & $0.98 \pm 1.26$ & 0.155 \\
\hline Emotional eater (Yes / No) ${ }^{\text {a }}$ & $24.4 \%(38) /$ & $23.1 \%(24) /$ & $26.9 \%(14) /$ & 0.742 \\
& $75.6 \%(118)$ & $76.9 \%(80)$ & $73.1 \%(38)$ & \\
\hline
\end{tabular}

EEQ: Emotional Eater Questionnaire, WG: Gain Weight, NWG: Not Gain Weight, *p<0.05 and significant. As determined by the Mann-Whitney U test. ${ }^{a}$ As determined by the chi-square test.

Table 4: Scale Results by Age.

\begin{tabular}{|c|c|c|c|c|c|c|}
\hline & \multicolumn{2}{|c|}{ 65-74 years } & \multicolumn{4}{|c|}{ Over 75 years } \\
\hline & NWG, $n=38$ & WG, $n=72$ & $\mathbf{p}$ & NWG, $n=14$ & WG, $n=32$ & $\mathbf{p}$ \\
\hline $\begin{array}{l}\text { Fear of Covid-19 } \\
\text { score }\end{array}$ & $21.55 \pm 6.77$ & $22.98 \pm 5.99$ & 0.286 & $24.14 \pm 6.05$ & $22.63 \pm 7.87$ & 0.886 \\
\hline EEQ score & $6.42 \pm 6.02$ & $8.21 \pm 4.74$ & $0.048 *$ & $5.79 \pm 4.98$ & $6.75 \pm 4.87$ & 0.303 \\
\hline Disinhibition & $3.53 \pm 3.67$ & $4.57 \pm 3.15$ & 0.061 & $3.57 \pm 3.74$ & $3.66 \pm 3.05$ & 0.571 \\
\hline Type of food & $1.82 \pm 1.54$ & $2.26 \pm 1.28$ & 0.090 & $1.5 \pm 0.94$ & $2.16 \pm 1.39$ & 0.171 \\
\hline Guilt & $1.08 \pm 1.38$ & $1.38 \pm 1.33$ & 0.125 & $0.71 \pm 0.82$ & $0.94 \pm 1.29$ & 0.866 \\
\hline $\begin{array}{l}\text { Emotional } \\
(\text { Yes / No })^{a}\end{array}$ & $\begin{array}{c}28.9 \%(11) / \\
71.1 \%(27)\end{array}$ & $\begin{array}{c}26.4 \%(19) / \\
73.6 \%(53)\end{array}$ & 0.824 & $\begin{array}{l}21.4 \%(3) / \\
78.6 \%(11)\end{array}$ & $\begin{array}{l}15.6 \%(5) / \\
84.4 \%(27)\end{array}$ & 0.684 \\
\hline
\end{tabular}

EEQ: Emotional Eater Questionnaire, WG: Gain Weight, NWG: Not Gain Weight, *p<0.05 and significant. As determined by the Mann-Whitney $\mathrm{U}$ test. ${ }^{\mathrm{a}}$ As determined by the chi-square test.

Current BMI, overall EEQ score, and EEQ disinhibition and type-of-food subscores were weakly positively correlated with change in $\triangle \mathrm{BMI}$ (Table 5). Other variables were not associated with $\Delta B M I$ ( $p>0.05)$.
Guilt score was weakly positively correlated with age. Other variables were not associated with age ( $>00.05)$, (Table $5)$. 
S. Ercan et al.

Table 5: Variables associated with $\triangle \mathrm{BMI}$ and age.

\begin{tabular}{|c|c|c|c|}
\hline & & Change in BMI ( $\Delta \mathrm{BMI})$ & Age \\
\hline \multirow[t]{2}{*}{ Change in BMI } & r value & 1 & 0.013 \\
\hline & $\mathrm{p}$ value & - & 0.876 \\
\hline \multirow[t]{2}{*}{ Age } & r value & 0.013 & 1 \\
\hline & $\mathrm{p}$ value & 0.876 & - \\
\hline \multirow[t]{2}{*}{ Pre-pandemic BMI } & $\mathrm{r}$ value & 0.028 & -0.058 \\
\hline & $\mathrm{p}$ value & 0.727 & 0.469 \\
\hline \multirow[t]{2}{*}{ Current BMI } & r value & $0.338^{* *}$ & -0.076 \\
\hline & $\mathrm{p}$ value & 0.0001 & 0.348 \\
\hline \multirow[t]{2}{*}{ Fear of Covid-19 score } & r value & 0.155 & 0.082 \\
\hline & $\mathrm{p}$ value & 0.054 & 0.308 \\
\hline \multirow{2}{*}{$\begin{array}{l}\text { Emotional Eater Questionnaire } \\
\text { score }\end{array}$} & r value & $0.209^{* * *}$ & -0.145 \\
\hline & $\mathrm{p}$ value & 0.009 & 0.071 \\
\hline \multirow{2}{*}{ Disinhibition } & r value & 0.161* & -0.106 \\
\hline & $\mathrm{p}$ value & 0.044 & 0.190 \\
\hline \multirow{2}{*}{ Type-of-food } & r value & $0.245^{* *}$ & -0.055 \\
\hline & $\mathrm{p}$ value & 0.002 & 0.498 \\
\hline \multirow{2}{*}{ Guilt } & r value & 0.106 & $0.229 * *$ \\
\hline & $\mathrm{p}$ value & 0.188 & 0.004 \\
\hline
\end{tabular}

BMI: Body Mass Index, *Correlation is significant at $\mathrm{p}<0.05$ (2-tailed), **Correlation is significant at $\mathrm{p}<0.01$ (2-tailed). As determined by Spearman's correlation analysis.

\section{Discussion}

In this study, we investigated fear of Covid-19, emotional eating behaviour, and physical activity levels in elderly people aged $>65$ years, who had to stay at home for extended durations of time during the pandemic, and who were primarily at risk of infection. The study included data from 156 participants. Accordingly, participants who did and who did not gain weight were similar in terms of fear of Covid-19 pandemic and physical activity levels. Even though the number of participants classified as "emotional eaters" according to the Emotional Eater Questionnaire was similar for the two groups, participants who gained weight during the pandemic scored significantly higher in the EEQ type-of-food subscale $(\mathrm{p}=0.029)$. Current BMI, overall EEQ score, and EEQ disinhibition and type-of-food subscores were weakly positively correlated with change in BMI and guilt score was weakly positively correlated with age. Moreover, participants in the NWG group were more likely to have first-degree relatives diagnosed with Covid-19 ( $\mathrm{p}=0.011$ ).

Rodriguez et al. conducted a study of 400 elderly individuals aged 60 to 86 , and demonstrated that the Fear of Covid-19 score was higher in women than men, and that higher Covid-19 knowledge was associated with a higher fear of Covid-19 (9). They did not find any correlation between having a relative diagnosed with Covid-19 and fear scores but reported that older participants had lower fear scores (9). Haktanir et al. found that fear of Coronavirus was not significantly associated with age, chronic disease status, or education status, and that individuals aged over 60 years (16.87 points) scored lower on the fear of Covid-19 scale than individuals aged 50-59 (18.00 points), 


\section{S. Ercan et al.}

although this difference was not statistically significant (18). This finding was ascribed to the increased sense of safety associated with increased social isolation (19). Although the results reported in the literature regarding the relationship between age and fear of Coronavirus vary $(9,18,20,21)$, the general opinion is that the elderly are less informed about the disease, and therefore are less anxious and less likely to protect themselves (22).

Again, Haktanır et al. reported a higher fear of Covid-19 among female participants than males. This finding was attributed to the higher response to stress in women (18). A different study found a positive and significant correlation between fear of Coronavirus and anxiety and depression (23). Ahorsu et al. showed that fear of Coronavirus is not affected by sex or age (7). To the best of our knowledge, there are no studies in the literature that investigate the relationship between body mass index and the fear of Covid-19. In this study, we did not find an association between change in weight and fear of Coronavirus in individuals aged over 65 years. As described above, the literature presents various results for different variables in the context of fear of Covid-19. We believe that these differences may be partially due to the different pandemic management strategies adopted by different countries. For this reason, we believe that assessing each society individually can produce more reliable results.

A study by Renzo et al. evaluated emotional eating behaviour during the Covid-19 quarantine (4). Most of their participants had symptoms of depression (61.3\%), anxiety (70.4\%), hypochondriasis $(61.2 \%)$, and insomnia (52.2\%). Moreover, participants reported feeling anxious due to their changing eating habits $(48.7 \%)$, that they consumed an increased amount of food as a response to anxiety (57.8\%), and ate for comfort $(55.1 \%)$. Younger age, a lower BMI, less anxiety and mood changes, and a smaller tendency to increase food intake for comfort were associated with better eating control (4). A study of 638 female subjects aged 18-39 by Al-Musharaf showed that $47.2 \%$ of women had low EEQ scores, $40.4 \%$ had moderate EEQ scores, and $12.4 \%$ had high EEQ scores (i.e., were emotional eaters) (10). Also, among these women, $42.8 \%$ reported depression, $27 \%$ anxiety, $71 \%$ moderate stress, and $12.5 \%$ severe stress. Emotional eating scores were positively correlated with fat intake, number of meals, sugary food consumption, body mass index, stress, energy intake, and fast-food consumption. Shen et al. reported moderate to high perceived stress in $73.6 \%$ of their subjects. In addition, they reported emotional eating behaviour and food choice motives were associated with mood, convenience, price, and familiarity $(p<0.05)$, and perceived stress was statistically correlated with emotional eating behaviour ( $r=0.2)$ (24).

A study by Papandreou et al. examined the effect of different isolation protocols from two different countries on eating behaviour and mood changes in individuals aged 18 and over (25). In Spain, 13.6\% and 12.3\% of the participants showed symptoms of moderate and severe depression and anxiety, while in Greece, these numbers were $18.8 \%$ and $13.2 \%$, respectively. Participants from Spain scored statistically lower on the Emotional Eater Questionnaire compared to participants from Greece $\quad(p<0.001)$ Similarly, participants from Spain reported fewer 


\section{S. Ercan et al.}

restrictions $(\mathrm{p}<0.001)$. In addition, a higher weight gain was reported in the Greek population. In our study, EEQ overall and type-of-food subscale scores were significantly higher in participants who gained weight during the pandemic. The literature reports that the change in BMI and food choice and disinhibition are correlated (25). In our study, we found that the fear of Covid-19 was similar among individuals who did and did not gain weight during the pandemic. We did not find a correlation between emotional eating and fear of Covid-19. Accordingly, it can be said that the fear of Covid-19 does not trigger emotional eating behavior in the elderly.

Increased inactivity during the Covid-19 pandemic can potentially increase morbidity and mortality among the elderly, especially if the lockdown is further extended (26). Antunes et al. investigated physical activity levels of 1404 participants aged 18-89 during the Covid-19 pandemic and reported that 447 participants $(31.8 \%)$ had low physical activity, 697 people (49.6\%) moderate physical activity, and 260 participants $(18.5 \%)$ had high physical activity (27). Lesser et al. used the Godin Leisure Questionnaire to assess individuals over the age of 19 and classified $63.4 \%$ $(\mathrm{n}=694)$ of their participants as inactive and $36.6 \%(\mathrm{n}=404)$ as physically active (28). They demonstrated that $40.5 \%$ of sedentary individuals and $22.4 \%$ of active individuals became less active and $33 \%$ of sedentary individuals and $40.3 \%$ of physically active individuals became more active during the pandemic (28). In our study, $41.7 \%$ of the elderly were classified as active, $30.1 \%$ as moderately active, $23.1 \%$ as moderately inactive, and $5.1 \%$ as inactive. Participants who did and did not gain weight during the pandemic were not statistically different in terms of physical activity. Therefore, we believe weight gain during the pandemic was not associated with physical inactivity but emotional eating behaviours, such as comfort eating and disinhibition.

The limitations of our research are its cross-sectional design, the limited representativeness of the sample, and having based psychological assessment on self-reported data.

To conclude, participants who did and did not gain weight during the pandemic were not different in terms of the fear of Covid19 scores and physical activity levels. Body mass index was statistically associated with Emotional Eater Questionnaire scores. Eating habits and preferences of the elderly changed during the Covid-19 quarantine. Elderly individuals need psychological support to reduce emotional eating behavior and should be directed to physical activity for weight control and to become more active.

\section{Conflict of Interest}

The authors declare that they have no conflict of interest.

\section{Acknowledgment}

No institution has given financial support to the study. All researchers contributed equally to the study.

\section{References}

1. Yamada M, Kimura Y, Ishiyama D, et al. Effect of the COVID-19 Epidemic on Physical Activity in Community-Dwelling Older Adults in Japan: A Cross-Sectional Online Survey. J Nutr Heal Aging. 2020;24(1):948-50.

2. WHO Coronavirus Disease (COVID-19) Dashboard [Internet]. Available from: https://COVID19.who.int/

3. Republic of Turkey Ministry Covid-19 


\section{S. Ercan et al.}

Information Page [Internet]. Available from: https://COVID19.saglik.gov.tr/EN-69532/generalcoronavirus-table.html

4. Di Renzo L, Gualtieri P, Cinelli G, et al. Psychological Aspects and Eating Habits during COVID-19 Home Confinement: Results of EHLCCOVID-19 Italian Online Survey. Nutrients. 2020;12(7):2152.

5. Hall RCW, Chapman MJ. The 1995 Kikwit Ebola outbreak: lessons hospitals and physicians can apply to future viral epidemics. Gen Hosp Psychiatry. 2008;30(5):446-52.

6. Ho SMY, Kwong-Lo RSY, Mak CWY, et al. Fear of severe acute respiratory syndrome (SARS) among health care workers. J Consult Clin Psychol. 2005;73(2):344-9.

7. Ahorsu DK, Lin CY, Imani V, et al. The Fear of COVID-19 Scale: Development and Initial Validation. Int J Ment Health Addict. 2020;1-9.

8. Nguyen HT, Do BN, Pham KM, et al. Fear of COVID-19 Scale-Associations of Its Scores with Health Literacy and Health-Related Behaviors among Medical Students. Int J Environ Res Public Health. 2020;17(11):4164.

9. Caycho-Rodríguez T, Tomás JM, BarbozaPalomino M, et al. Assessment of Fear of COVID19 in Older Adults: Validation of the Fear of COVID-19 Scale. Int $\mathbf{J}$ Ment Health Addict. 2021;1-15.

10. Al-Musharaf S. Prevalence and Predictors of Emotional Eating among Healthy Young Saudi Women during the COVID-19 Pandemic. Nutrients. 2020;12(10):2923.

11. Đogaš Z, Kalcina LL, Dodig IP, et al. The effect of COVID-19 lockdown on lifestyle and mood in Croatian general population: A crosssectional study. Croat Med J. 2020;61(4):309-18.

12. Luo M, Guo L, Yu M, et al. The psychological and mental impact of coronavirus disease 2019 (COVID-19) on medical staff and general public - A systematic review and metaanalysis.Psychiatry Res. 2020;113190.

13. Brooks SK, Webster RK, Smith LE, et al. The psychological impact of quarantine and how to reduce it: rapid review of the evidence. The Lancet. 2020;395(102227):912-20.

14. Bakioğlu F, Korkmaz O, Ercan H. Fear of COVID-19 and Positivity: Mediating Role of Intolerance of Uncertainty, Depression, Anxiety, and Stress. Int J Ment Health Addict. 2020;1-14.

15. Arslantaş H, Dereboy F, Yüksel R, et al. Validity and Reliability of the Turkish Version of the Emotional Eater Questionnaire (EEQ-TR). Turkish J Psychiatry. 2020;31(2):122-30.

16. Kaya Noğay AE, Özen M. Birinci Basamak İçin Fiziksel Aktivite Anketinin Türkçe
Uyarlamasının Geçerlilik ve Güvenilirliği. Konuralp Tip Derg. 2019;11(1):1-8.

17. Garaulet M, Canteras M, Morales E, et al. Validación de un cuestionario de comedores emocionales para uso en casos de obesidad; cuestionario de comedor emocional (CCE). Nutr Hosp. 2012;27(2):645-51.

18. Haktanir A, Seki T, Dilmaç B. Adaptation and evaluation of Turkish version of the fear of COVID-19 Scale. Death Stud. 2020;1-9.

19. Andrade EF, Pereira LJ, Oliveira APL de, et al. Perceived fear of COVID-19 infection according to sex, age and occupational risk using the Brazilian version of the Fear of COVID-19 Scale. Death Stud. 2020;1-10.

20. Meng $\mathrm{H}, \mathrm{Xu} \mathrm{Y}$, Dai J, et al. Analyze the psychological impact of COVID-19 among the elderly population in China and make corresponding suggestions. Psychiatry Res. 2020;(289):112983.

21. de Leo D, Trabucchi M. COVID-19 and the Fears of Italian Senior Citizens. Int J Environ Res Public Health. 2020;17(10):3572.

22. Soraci P, Ferrari A, Abbiati FA, et al. Validation and Psychometric Evaluation of the Italian Version of the Fear of COVID-19 Scale. Int J Ment Health Addict. 2020;1-10.

23. Caycho-Rodríguez T, Vilca LW, Cervigni M, et al. Fear of COVID-19 scale: Validity, reliability and factorial invariance in Argentina's general population. Death Stud. 2020;1-10.

24. Shen W, Long LM, Shih $\mathrm{CH}$, et al. A humanities-based explanation for the effects of emotional eating and perceived stress on food choice motives during the COVID-19 pandemic. Nutrients. 2020;12(9):1-18.

25. Papandreou C, Arija V, Aretouli E, et al. Comparing eating behaviours, and symptoms of depression and anxiety between Spain and Greece during the COVID-19 outbreak: Cross-sectional analysis of two different confinement strategies. Eur Eat Disord Rev. 2020;28(6):836-46.

26. Roschel H, Artioli GG, Gualano B. Risk of Increased Physical Inactivity During COVID-19 Outbreak in Older People: A Call for Actions. J Am Geriatr Soc. 2020;68(6):1126-8.

27. Antunes R, Frontini R, Amaro N, et al. Exploring Lifestyle Habits, Physical Activity, Anxiety and Basic Psychological Needs in a Sample of Portuguese Adults during COVID-19. Int J Environ Res Public Health. 2020;17(12):4360. 28. Lesser IA, Nienhuis CP. The Impact of COVID-19 on Physical Activity Behavior and Well-Being of Canadians. Int J Environ Res Public Health. 2020;17(11):3899. 